ADRIÁN RESTREPO PARRA*

Universidad de Antioquia (Medellín, Colombia)

\title{
Acción política cannábica en la ciber-realidad ${ }^{*}$
}

\author{
Cannabis political action in cyber-reality
}

Ação política cannábica na Ciber-realidade

\footnotetext{
* Profesor del Instituto de Estudios Políticos de la Universidad de Antioquia. Magíster en Ciencia Política. Candidato a doctor en Ciencias sociales y humanas. Integrante de los grupos de investigación «Hegemonía, guerras y conflictos» del Instituto de Estudios Políticos y del grupo RERDSA del Instituto de Estudios Regionales, INER, ambos de la Universidad de Antioquia. Correo electrónico: adrian.restrepo@udea.edu.co. ORCID: https://orcid.org/oooo-ooo2-0970-1028.

** Este artículo es resultado de la investigación «Ciudadanos consumidores de drogas», registrada en el Sistema Universitario de Investigación (SUI) de la Universidad de Antioquia y realizada en el Instituto de Estudios Políticos de la misma universidad. Durante cinco años (2012-2017) se realizaron 50 entrevistas a los activistas de las principales ciudades de Colombia, rastreo semanal de las publicaciones de los activistas en Facebook. Además, el estudio cuenta con vídeo grafía y clasificación de información en el software Nvivo. El sistema bibliográfico reposa en el software Zotero. La dinámica investigativa condujo a la producción del documental «Nuestro derecho al cannabis», disponible en esta dirección: https:// youtu.be/7AoI6R98TPU. Artículo de investigación recibido el 22.08.2017 y aceptado el 11.12.2017.
} 


\section{Cómo citar}

RESTREPO PARRA, A. (2018). Acción política cannábica en la ciber-realidad. Revista CS, (24), 19-40.

DOI: http://dx.doi.org/10.18046/recs.i24.2474 
Resumen

Abstract

Resumo

Este artículo aborda el papel de la Internet en general y el Facebook en particular en el surgimiento y configuración de los activistas cannábicos organizados como Comunidad Cannábica Colombiana-CCC-. La creación de perfiles, grupos y contactos en Facebook por parte de los distintos activistas cannábicos constituyen un espacio de comunicación constante que fortalece la acción colectiva. Ese espacio combina tres asuntos centrales: 1) fortalece la confrontación organizada de una situación de exclusión, 2) permite el conocimiento mutuo e identificación colectiva entre activistas del movimiento cannábico y 3) posibilita el proceso de organización y acción colectiva de los consumidores de cannabis en Colombia.

\section{PALABRAS CLAVE:}

Ciber-realidad; Cannabis; Facebook; Internet; Exclusión; Acción colectiva.

This article analyses the role of the Internet in general and Facebook in particular in the emergence and configuration of cannabis activists organized as Colombian Cannabis Community (CCC). The creation of profiles, groups and contacts on Facebook by the various activists constitute a constant communication space that strengthens the activist's cannabis action as a whole. This space combines three central issues: 1) strengthens the organized confrontation of a situation of exclusion, 2) allows mutual knowledge and collective identification between activists of the cannabis movement and 3 ) enables the process of organization and collective action of cannabis users in Colombia.

\section{KEYWORDS:}

Cyber-reality; Cannabis; Facebook; Internet; Exclusion; Collective action. 
Este artigo aborda o papel da internet em geral e o Facebook em particular no surgimento e configuração dos ativistas cannábicos organizados como Comunidade Cannábica Colombiana (CCC). A criação de perfis, grupos e contatos no Facebook por parte dos diferentes ativistas cannábicos constituem um espaço de comunicação constante que fortalece a ação coletiva. Esse espaço combina três assuntos centrais: 1) fortalece o confronto organizado de uma situação e exclusão, 2) permite o conhecimento mútuo e identificação coletiva entre ativistas do movimento cannábico e 3) possibilita o processo de organização e ação coletiva dos consumidores de maconha na Colômbia.

\section{PALAVRAS CHAVES:}

Ciber-realidade; Canabis; Facebook; Internet; Exclusão; Ação coletiva. 


\section{Introducción}

Este artículo aborda el surgimiento y la configuración de la Comunidad Cannábica Colombiana-CCC-, organización que agrupa a un sector de los activistas del movimiento cannábico de Colombia. En tal proceso, destaca el papel de la Internet en general y el Facebook en particular. Aspectos importantes por tres cuestiones básicas: 1) por el debate internacional y nacional de la políticas de drogas con enfoque prohibicionista; 2) porque en ese debate un actor silenciado y ausente han sido los consumidores de drogas como el cannabis; y 3) por el vital rol que desempeñan las tecnologías en la esfera de la política y la acción colectiva para que los activistas luchen por sus derechos profundizando la democracia pluralista.

Estos tres asuntos convergen en Colombia, un país tradicionalmente asociado, a nivel internacional, al narcotráfico; y donde la guerra entre Estado, guerrillas y paramilitares resultó envuelta en la guerra contra las drogas. En estas violencias cruzadas surge el movimiento social cannábico, a través del cual los ciudadanos consumidores luchan por sus derechos. El análisis realizado sigue las orientaciones teóricas de los derechos como resultados de las luchas por las ciudadanías (Tilly, 2004). ${ }^{1}$

La contienda ciudadana por el derecho al consumo de cannabis empieza en un contexto marcado por la marihuanofobia, situación de odio al consumidor ${ }^{2}$ de marihuana (Restrepo, 2017). En Colombia este odio ha tenido manifestaciones como los grupos de «limpieza social», los cuales han amenazado y asesinado a los «viciosos» con el propósito de limpiar el barrio y a la ciudad de la «suciedad», y promover así su particular visión de la pulcritud moral. Aunque en Colombia no existe legalmente la pena de muerte para los consumidores de marihuana, por las vías de hecho se ha implementado. La persecución al consumidor la han ejercido diferentes grupos armados, bien porque moralmente los consideran «mal ejemplo» o bien porque pueden obtener beneficios de la población al darle a la mayoría lo que piden: «muerte al vicioso».

La marihuanofobia comporta un proceso de exclusión de los consumidores de marihuana. La fase última de ese proceso es la muerte, la pérdida violenta de la vida, pero esa situación extrema tiene, por su carácter de proceso, otros momentos y vías

1. Para seguir esta perspectiva, la investigación siguió metodológicamente el enfoque de la etnografía y la ciber etnografía. Especialmente la orientación de Guber (2001) de privilegiar la perspectiva del actor, en este caso los consumidores de cannabis. Consecuente con este enfoque, los entrevistados firmaron consentimientos informados autorizando el uso público de sus nombres y de la información suministrada. El enfoque también incidió en el estilo de escritura y en el uso de algunas citas en el texto.

2. Utilizamos el concepto de consumidor con el propósito de señalar la racionalidad de mercado que está inmiscuida en la práctica contemporánea del consumo de marihuana. 
de acción. En la vida de los marihuaneros ${ }^{3}$ que hacen parte de la CCC, la «echada» es una palabra recurrente y constante en sus relatos a la hora de narrar experiencias como consumidores de marihuana en un régimen de prohibición y guerra contra las drogas. Desde el drama de temer a ser echado de la familia, especialmente por la mamá, hasta ser echado del colegio, del trabajo, etc., son todas ellas prácticas que tornean algunas dimensiones de las situaciones de exclusión que viven los consumidores de cannabis.

Historias individuales que superan el drama personal y develan un conflicto social y político. Justamente porque los activistas cannábicos han llegado a una conclusión en tal perspectiva, ha surgido la figura del activista, la presencia pública, visible y masiva de los consumidores de marihuana en Colombia. La CCC es una de las expresiones del movimiento cannábico colombiano. La existencia de esta expresión colectiva tiene entre sus manifestaciones el malestar por la implementación de la política que ha declarado una guerra contra las drogas y sus consumidores. Una política que, a juicio de los activistas, los ha victimizado. Ante esta situación surge la gesta de la acción política: tienen lugar, entre otras actividades, las marchas cannábicas en las principales ciudades del país, la creación de colectivos cannábicos en 28 ciudades y la organización nacional Comunidad Cannábica Colombiana-CCC-.

En el surgimiento y consolidación de la CCC, la Internet y las redes sociales como Facebook han jugado un papel importante. El activismo offline, con el cual empezó la CCC, ha sido fortalecido por las posibilidades que ofrece el activismo online. Ambos se entrelazan y constituyen un repertorio de acción política que permite simultáneamente la conformación organizativa de un sujeto colectivo y la realización misma de la acción política cannábica que este desarrolla. Para analizar el proceso de configuración de la acción colectiva cannábica, acompasada por la participación en las redes sociales y el uso de ellas, este artículo consta de cuatro partes: 1) La exclusión del marihuanero; 2) Activistas y colectivos cannábicos; 3) Repertorio de acción del movimiento cannábico; y 4) Consideraciones finales.

3. Esta palabra usualmente ha estado cargada de connotaciones negativas, aunque también ha sido asumida por algunos usuarios de marihuana como parte de su identidad. Situación conducente a un debate interno en la CCC sobre si denominarse marihuaneros o cannábicos. 


\section{La exclusión del marihuanero ${ }^{4}$}

La discriminación que viven los consumidores de marihuana empieza en la familia. Los jóvenes consumidores ${ }^{5}$ de marihuana no realizan su consumo en la casa porque la familia, especialmente los padres, prohíben su consumo:

Hay muchas personas que de pronto hacen uso de la cannabis pero no le pueden decir a nadie, nadie se puede enterar, si no sería terrible [...] gente que de pronto ha fumado durante muchísimos años pero que jamás se ha atrevido a afrontarlo con su familia [...]. Me pueden echar de la casa, van a pensar que me voy a volver un habitante de calle (Entrevista personal, Mauricio Romero, Huerta rebelde, Bogotá, septiembre de 2015).

En la familia la política de la prohibición y la guerra contra las drogas «se coló» bajo la figura del miedo al «enfermo y el delincuente», condensada en la realidad del habitante de calle. Consumir marihuana es percibido por algunos miembros de la familia como el camino a la perdición del consumidor y de los demás, «el mal ejemplo». Las familias, especialmente de estratos bajos, no quieren tener como miembro un indigente en potencia, el marihuanero.

La política de infundir el miedo a las drogas constituye una forma de educar a los jóvenes. ${ }^{6}$ Esta educación conlleva además una serie de prácticas. Las advertencias hacen parte de esta educación, las realizadas por los padres a sus hijos terminan, quizás sin pensarlo, en amenazas. No es solo que la familia repita en parte el discurso prohibicionista según el cual las drogas per se son malas y peligrosas o que quienes las consumen son «enfermos y delincuentes»; es algo más grave aún. Según narran los entrevistados, los familiares en su afán de prohibir el consumo de marihuana u otra droga ilegal (porque las legales no están en discusión) ejercen una autoridad carente de información y conocimiento científico sobre las drogas, imponen obediencia fundada en el miedo, en el uso de la violencia. El castigo empieza con la reprimenda, pasando en algunos casos por la paliza porque el chico llegó a casa con «los ojos rojos y oliendo a marihuana», hasta culminar con el destierro, echar

4. Este apartado fue relaborado retomando el texto de Restrepo (2017).

5. Según el Reporte de Drogas de Colombia «Aproximadamente el 62\% de los consumidores de marihuana son personas que tienen entre 12 a 24 años y casi el $87 \%$ de los consumidores tienen menos de 34 años» (Gobierno Nacional et al, 2014:15).

6. Aquí no está en discusión la educación de los jóvenes en drogas, sino la orientación brindada por el enfoque prohibicionista, «un mundo libre de drogas», que según las tendencias globales de políticas de drogas está en cuestión. 
al consumidor de la casa. Echar al consumidor es una práctica que se reproduce en otros espacios como el sistema educativo:

A un joven que encontraban en un colegio fumando marihuana lo más probable que hacían era echarlo del colegio rápidamente, porque bajo el concepto de que una manzana podrida pudre al resto, entonces había que sacar ese usuario para que ese consumo no se propagara en las instituciones, ¿eso qué generó? Una desescolarización muy grave que, pues solo es una forma de negar el derecho a la educación de todos los ciudadanos (Entrevista personal, David Ponce, Comunidad Cannábica Colombiana, Medellín, Marzo de 2015).

La echada es una constante en los relatos de los consumidores de marihuana entrevistados en este estudio. Algunos la han vivido directamente, otros conocen historias cercanas y, cada uno, siente que ese es el riesgo que corren por consumir marihuana, aun siendo avalada por la ley.7 Bajo la política del miedo, los consumidores buscan los medios posibles para evitar que especialmente su familia se entere, quedándoles como opción, dada la sistemática discriminación que viven, ir a consumir a la calle:

Como en el hogar empieza el problema pues yo decido salir a usar la sustancia en la calle ¿no? Porque pues yo nunca he sido de estar mucho en la calle, igual por la costumbre familiar; entonces si yo iba a consumir marihuana y eso, estaba tomándome la libertad de hacerlo en casa, pero cuando veo que están, digamos, enojándose mis papás y mis hermanos, entonces decido salir a la calle y ahí vienen los problemas con la policía, pues uno lo hace en un parque (Entrevista personal, Ray Rozo, UPN Pedagogía de las Drogas, Bogotá, Septiembre de 2015).

Echados de distintas partes, los consumidores terminan en un lugar público, justamente el espacio legalmente prohibido para ello. Los riesgos y conflictos por ocupar el espacio público para consumir parecen imponerse como parte del ejercicio del derecho del ciudadano para drogarse. Los consumidores de marihuana, especialmente los jóvenes, que no pueden hacerlo en sus casas ni en otros lugares, terminan así ocupando de manera masiva ${ }^{8}$ y regular diferentes parques en el país. Esta no es una preocupación nueva ni para las alcaldías ni para algunos sectores de

7. La Corte Constitucional de Colombia por medio de la sentencia C-221 de 1994 despenalizó el porte y el consumo de marihuana. Según este fallo, el consumidor de marihuana tiene derecho a portar 20 gramos de marihuana y cultivar hasta 20 plantas.

8. Según el Reporte de Drogas de Colombia del año 2016 «unas 763 mil personas consumieron marihuana en el último año, de las cuales 607 mil son varones, indicaría el 79\%». (Gobierno Nacional et al, 2014: 77). 
la sociedad. La historia colombiana del trato al consumidor de marihuana registra intereses «coincidentes» con la prohibición y la guerra contra las drogas que no puede desligarse, por ejemplo, de los procesos -directos o colaterales- de conformación de grupos de «limpieza social» (Perea, 2016) para exterminar a los consumidores de cannabis:

Los mismos vecinos del barrio se encargaban y mataban los viciosos, como decían en ese tiempo, pero se encargaban y hacían unos grupos al margen e iban y les daban machete, en ese tiempo no existía tanto la bala, pero sí mataban a machete por el mero hecho de una persona consumir marihuana (Entrevista personal, Olmes Ortiz, Comunidad Cannábica Colombiana, Medellín, Mayo de 2015).

El relato de Olmes Ortiz, el presidente de la Comunidad Cannábica Colombiana, evoca los años 70 en Medellín, cuando él empezó a consumir una planta que considera sagrada. Las masacres en lugares donde los consumidores de marihuana suelen reunirse hacen parte de la historia de represión contra estos ciudadanos, es el culmen del odio al marihuanero. Pero esta historia es una historia viva. Por ejemplo, Diego Urrea contó que: «los panfletos amenazantes todavía aparecen en algunas localidades advirtiendo que van acabar con los problemas del sector: con los marihuaneros, las putas y los maricas» (Entrevista personal, Diego Mauricio Urrea, Consuma Responsabilidad, Armenia, Marzo de 2015).

Bajo el estigma marihuanero (Goffman, 2003), los grupos armados de distinta naturaleza han acudido a las llamadas acciones de «limpieza social» como forma de ganar aceptación. En esas labores los marihuaneros han sido los primeros en ser perseguidos hasta el asesinato. Los lugares sucios y oscuros parecen un distintivo de los sitios donde finalmente terminan los consumidores; por ejemplo, El Piojo nos contó que «en la Universidad del Quindío los colinos ${ }^{9}$ quedaron ubicados, después de la persecución de las directivas, al lado del basurero» (Entrevista personal, Diego Urrea, Consuma Responsabilidad, Armenia, marzo de 2015). Tal asociación, basura y marihuaneros, manifiesta nuevamente la injuria, una lesión a la autoestima del consumidor porque su estilo de vida es considerado así por sus conciudadanos como algo sucio y que debe ser arrojado a la basura, salir de la circulación de lo público, el marihuanero es tratado como «algo», una cosa, es lo que Honneth denomina reificación (Honneth, 2012).

El odio al marihuanero causa lesiones a los derechos fundamentales del consumidor de cannabis. Son formas de menosprecio que afectan la conformación de la identidad autónoma, son prácticas que socavan el derecho al libre desarrollo de

9. Colino es una palabra usada en el argot cannábico para referirse a un consumidor de marihuana. 
la personalidad y que, en su conjunto, lo conducen a la exclusión (Cortés, 2002). Esta conclusión parcial está en la base del juicio de los cannábicos, según el cual son víctimas de la política de la guerra contra las drogas que trunca el derecho al ejercicio libre de la autonomía, por lo cual la consideran una política injusta que amerita ser cambiada.

\section{Activistas y colectivos cannábicos en acción}

A partir de la experiencia personal de vivir la exclusión por consumir marihuana, distintas personas consumidoras reflexionan sobre su situación y comparten sus valoraciones, principalmente con los amigos. La injusticia y la indignación movilizan a sujetos que encuentran en la acción colectiva una posibilidad de actuación social y política para cambiar ese estado de cosas, es decir, surge el activista cannábico. Sobre este aspecto es interesante esta reflexión:

Cuando el orden tradicional de la sociedad excluye a grupos de individuos y no los reconoce, éstos no tienen más remedio que hacerse oír y expresar sus necesidades, para lo cual es inevitable que se organicen e inserten su yo individual en un yo colectivo. Los movimientos y las organizaciones sociales no tienen otro objetivo que proporcionar a sus asociados el marco adecuado para existir de un modo distinto a como venían existiendo, y para recabar un reconocimiento no conseguido hasta entonces (Camps, 2011: 226-227).

Para el caso de los cannábicos, los activistas crean colectivos en sus respectivas ciudades, una forma de organización básica con capacidad de incidencia social y política. Estas formas organizativas se consolidan por medio de la participación en las actividades que desarrollan en espacios y escenarios públicos, entre ellos las redes sociales como Facebook. Formas organizativas que permiten el posicionamiento de debates y hechos favorables para los consumidores de marihuana, particularmente los referidos al cambio del enfoque prohibicionista para tratar el asunto de la producción, venta y consumo de drogas ilegales. Un propósito de tal alcance ha hecho que los activistas consoliden una organización nacional: la Comunidad Cannábica Colombiana-CCC-.

El surgimiento del activismo y de la CCC puede rastrearse en la realización de la primera marcha cannábica del país. Para hacerlo, seguiremos inicialmente el relato de Olmes Ortiz, actual presidente de la CCC. Las injusticias padecidas y la indignación generada, entre otros asuntos, incidieron en él para que tomara la iniciativa de convocar a una marcha y a la organización de los consumidores de marihuana para hacer 
respetar sus derechos. Olmes decidió que tenía que hacer algo $^{10}$ para detener los abusos en contra de los consumidores, hablando con sus amigos encuentra una posibilidad:

Demandando la ley 30, para la despenalización del uso de plantas psicoactivas, para desarrollar a la sociedad, en el autoanálisis que puede llevar el consumo de estas plantas, y percibir el mundo mejor desde el interior. Y entonces desde ahí parte este hecho, entonces desde ahí empiezo la acción, para la calle (Entrevista personal, Olmes Ortiz, Comunidad Cannábica Colombiana, Medellín, mayo de 2015).

Con la convicción de poder demandar el Estatuto Nacional de Estupefacientes y lograr respeto para los consumidores, Olmes, según sus palabras, se fue de «peregrinaje» para Bogotá con la idea de «hablarle a las personas poderosas para que cambien la ley 30 de estupefacientes». Recuerda:

Jorge Mejía me ilumina con ese dato de la despenalización del uso de plantas psicoactivas, en este caso la marihuana y la coca, entonces yo le digo: «¿Usted qué ha hecho para que esto se lleve a cabo?», él me hablaba del derrocamiento del estatuto de la Ley 30 ¿qué ha hecho? Le pregunto, y él me dijo: «había montado una acción de tutela, porque en la práctica se está violando el libre desarrollo de la personalidad y el libre derecho al culto». Y debido a eso yo fui a Bogotá a mirar la tutela, a buscar gente en el Congreso y después a crear un grupo para cambiar esto (Entrevista personal, Olmes Ortiz, Comunidad Cannábica Colombiana, Medellín, Mayo de 2015).

En la obstinación de Olmes, y apoyado por su amigo, él recuerda que logró hablar con una congresista, cuyas palabras en principio le parecieron ofensivas y luego las tomó como reto:

Una congresista en una intervención que hago me dice: «Una sola golondrina no hace verano», entonces ahí conlleva a hacer el grupo o a consolidar una unión, una unificación, porque verdaderamente una sola persona no era capaz, necesitábamos una masa. Llego a Medellín, después de ir a Bogotá para que el Congreso cambiara la ley 30, y hay alguien que me dice que yo siempre estaba hablando del derecho al uso y a la práctica con la marihuana y entonces me dice: «Pues si necesita gente, haga una marcha» y había aparecido la marcha gay, entonces yo dije «pues, si estos salen a legalizar su derecho, yo también puedo salir a legalizar que se me está violando un derecho» $\mathrm{y}$

10. Para el análisis es necesario hacer referencia a los liderazgos porque «el liderazgo tiene una función creativa a la hora de seleccionar las formas de la acción colectiva. Los líderes inventan, adaptan y combinan distintas formas de acción colectiva para estimular el apoyo de gente que, en caso contrario, podría quedarse en casa» (Tarrow, 2004: 47). 
empiezo a hacer la convocatoria para una posible marcha (Entrevista personal, Olmes Ortiz, Comunidad Cannábica Colombiana, Medellín, Mayo de 2015).

Convencido de la necesidad de hacer «un verano», Olmes emprende la tarea de hacer una marcha ${ }^{11}$ por el derecho a la marihuana. La convocatoria que realiza Olmes fue «voz a voz» entre amigos y conocidos. ${ }^{12}$ Los recursos eran escasos, igual que la experiencia en generar organizaciones de este tipo. El resultado en buena medida así lo confirmó. De manera jocosa, propia del estilo de Olmes, él dijo que esa primera marcha iba camino a ser una marcha de policías con marihuaneros porque la asistencia de marihuaneros fue muy poca. Tanto que finalmente decidió suspenderla para no dar el espectáculo de marchar con tantos policías. Era el año 2007, Olmes evoca ese momento:

Ese día me sentí muy triste, pero como siempre en todo, siempre hay un puentecito, hubo alguien que me dio moral, porque él me vio muy sentimental al ver que todo el esfuerzo de tantos años, porque yo venía con esto desde el 98 y que en tanto tiempo, en el 2007 apenas haya conglomerado 10 personas, que 10 personas hayan sido resonantes y junté otras 10, o sea que terminé con 20 personitas y 50 policías, entonces como esa impotencia (Entrevista personal, Olmes Ortiz, Comunidad Cannábica Colombiana, Medellín, Mayo de 2015).

La asistencia de la policía obedeció a que Olmes había radicado las autorizaciones necesarias para un evento público. Ante lo que Olmes en principio consideró un fracaso, llegaron las distintas explicaciones que luego serían «aliento» para continuar. Nos contó Olmes que una de las personas que asistió a la primera marcha (o al intento de primera marcha), se acercó a él para expresarle esto: «Nosotros los usuarios no te correspondimos a vos, pero vos te dijiste a ti mismo que sí eres capaz, que sí puedes y que esto sí se puede dar». Esas palabras causaron esta reacción en Olmes:

Y eso a mí me dio otra vez el espíritu y me volvió a emprender, y el usuario también me dijo: «Es la primera marcha, todo el mundo tenía miedo». Y después salí a las calles y la gente me comunicaba: «Hermano yo sí fui pero yo vi mucho policía y entonces yo

11. Este tipo de acción tiene incidencia política porque «la alteración del orden obstruye las actividades rutinarias de sus oponentes, de los observadores o de las autoridades y les fuerza a atender las demandas de los manifestantes» (Tarrow, 2004: 143).

12. Los ámbitos informales juegan su papel en la constitución del actor colectivo y las demandas: «los lazos informales que unen a los miembros de diferentes organizaciones en las campañas de protesta pueden llegar a crear redes sociales más amplias y una identidad colectiva que aglutine a miembros de diferentes organizaciones del movimiento» (Tarrow, 2004: 193). 
dije, no eso se le volteó a Olmes, entonces yo no me quise acercar, yo dije, no allá nos van a encanar, toda esa mana de tombos, ${ }^{13}$ eso fue que se volteó a Olmes», entonces eso también me daba otra satisfacción, porque yo decía: Sí fue gente, sino que vieron tanto policía que no se congregaron, además era la primera etapa. Entonces en eso sí me sentí muy triste, en el momento triste, pero después viene la recompensa que es la alegría de ver crecer la marcha (Entrevista personal, Olmes Ortiz, Comunidad Cannábica Colombiana, Medellín, Mayo de 2015).

Resultado de la evaluación de la primera marcha, Olmes tiene presente que entre los retos está vencer el miedo porque este es un sentimiento político consolidado bajo las distintas formas de represión para lograr controlar a los marihuaneros. Una medida para contrarrestar el miedo fue convocar masivamente a los consumidores, el carácter colectivo genera la sensación de seguridad. Con un poco más de apoyo, Olmes toma una decisión:

Empiezo la convocatoria para armar la marcha, para formar un grupo de impulso, y ahí ya aparece David Arango con la Comunidad Cannábica Colombiana, él me apoya mucho con la intervención y la difusión del hecho a través de las redes sociales y empieza a crecer y a generarse el grupo, que apenas hasta ahora después de tanto tiempo empieza a consolidarse, porque empiezan a aparecer los actores que verdaderamente conocen, saben y quieren participar de este tema (Entrevista personal, Olmes Ortiz, Comunidad Cannábica Colombiana, Medellín, Mayo de 2015, subrayado nuestro).

David es un joven, diseñador, inserto en las nuevas tecnologías de la comunicación, que apoyará ${ }^{14}$ a Olmes en la convocatoria de a una marcha por la marihuana. El manejo de internet y las redes sociales, algo que desconocía Olmes, permitirá hacer una amplia convocatoria que superaría inicialmente el número de convocados en el primer intento de marcha. A partir de este momento, surgen nuevos y más activistas que darán un impulso significativo a la marcha por la marihuana en distintas partes del país. ${ }^{15}$ David Arango también gesta el logo de Comunidad Cannábica Colombiana, como publicista hace los primeros trazos de lo que luego será acogido a nivel nacional como el nombre o distintivo de un sector del movimiento cannábico. David

\section{Policías.}

14. El trabajo conjunto entre David y Olmes está en la línea del planteamiento de Tarrow: «es el reconocimiento de una comunidad de intereses lo que traduce el movimiento potencial en una acción colectiva» (Tarrow, 2004: 28).

15. La marcha más grande es la de Medellín, donde se convocó la primera marcha. Los asistentes oscilaron entre 30 y 50 mil personas. 
nos contó que su inspiración para hacer el logo le vino encerrado en un calabozo cuando en un parque lo agarró la policía fumándose un porro, estaba aprovechando la hora del almuerzo en el receso laboral. En palabras de David Arango:

En parte fue bueno porque empecé a dibujar y a hacer el «loguito» de Comunidad Cannábica y en pensar una forma de cómo esto que me pasó a mí, que le pasó a un montón de gente, parce, pues que no era justo y que el fin original, el que yo creo que sigue siendo de la comunidad, no es salvar al mundo, ni legalizar la marihuana, ni no sé qué, parce, sino educarnos a nosotros de una forma que nosotros podamos educar a la tía, a la abuela, al señor agente (Entrevista personal, David Arango, Comunidad Cannábica Colombiana, Medellín, agosto de 2015).

Pasar de la idea del drama personal a la indignación colectiva, promueve la acción política, la búsqueda de un cambio en el obrar (Honneth, 1997). Los motivos para la acción tienden a fortalecerse cuando los activistas suscriben afirmaciones como esta de Escohotado «del mismo modo que ciertas enfermedades derivan directamente de los remedios arbitrados para curarlas, el actual problema mundial de drogas deriva de las medidas aplicadas para combatirlo» (Escohotado, 1998:376). Para los activistas la política de guerra contra las drogas hace parte principal del problema. Con el surgimiento de activistas como Olmes y David, empiezan a constituirse colectivos de activistas en las principales ciudades del país, ${ }^{16}$ quienes desarrollan un amplio abanico de actividades. Los colectivos cannábicos dieron lugar a encuentros nacionales ${ }^{17} \mathrm{de}$ activistas cannábicos-ENAC-. Resultado de estos, existe la Comunidad Cannábica Colombiana-CCC- como una realidad organizativa de alcance nacional.

\section{Repertorio de acción del movimiento cannábico}

Como reconoce Olmes en el apartado anterior, el encuentro con David Arango dará impulso a la marcha porque empiezan a constituir una organización y a convocar a los marihuaneros por medio de las redes sociales. La iniciativa surgida de las calles pasó a ocupar un espacio en las redes sociales y, en general, en la internet, es decir, en el online (Dalsgaard, 2016). Es tal el impacto de la internet, que Olmes literal-

16. Según Olmes Ortiz existen 28 colectivos de activistas en el país.

17. La constitución de colectivos y la creación de instancias de articulación entre estos puede entenderse en los términos de Tarrow: «las estructuras conectivas vinculan líderes con sus seguidores, el centro con la periferia y los diferentes sectores entré sí, permitiendo la coordinación y la optimización entre las organizaciones del movimiento y que éste perdure en el tiempo» (2004: 178). 
mente se vio obligado a incursionar en estos medios; ahora, como él mismo lo dice, es un hippie del siglo XXI porque usa Smartphone, Facebook, chats, videoclips, etc. Algo totalmente nuevo para él. Estar conectado con el movimiento y sus distintas dimensiones ha llevado a Olmes, en su calidad de presidente de la CCC, a hacer el mayor uso posible de estos medios sin descuidar el mundo offline (Dalsgaard, 2016), o sea la calle. Ambos escenarios permiten el despliegue de los repertorios de acción ${ }^{18}$ de los cannábicos.

\section{Repertorio offline}

Entre las motivaciones para la acción colectiva el agravio aparece como un incentivo. ${ }^{19}$ La motivación del activista a la acción entonces tiene como referencia la situación de marihuanofobia emanada de la política de guerra contra las drogas. Denunciar y transformar esa situación conduce al encuentro y articulación de distintos y diversos activistas cannábicos. David Arango, por ejemplo, nos cuenta algo sobre su experiencia:

¿Cuál es el fin o cómo se me ocurrió a mí que podía hacer algo? Era contándoles y haciendo lo que hacemos con la marcha que es una horda gigante de gente, parce, o sea, no es el marihuanero del frente, parce, son muchos marihuaneros; entonces no es un problema de cogerlos o encerrarlos, porque de encerrarlos enmallen a Medellín y ahí los cogió y ya (Entrevista personal, David Arango, Comunidad Cannábica Colombiana, Medellín, Agosto de 2015).

El carisma de Olmes, las capacidades artísticas y comunicativas de David Arango y la dedicación de David Ponce o Don Marcha al activismo promueven los medios de comunicación para debatir inicialmente el problema de los consumidores de marihuana, para eso proponen realizar una marcha cannábica. La marcha es un repertorio tradicional (Tarrow, 2004) utilizado por distintos actores colectivos. La marcha cannábica se caracteriza por autodenominarse como un carnaval cannábico, como dicen los organizadores, se trata de hacer una fiesta por la diversidad reclamando y exigiendo respeto (Bourgois, 2010) para los consumidores de marihuana. El carácter festivo tiene entre sus ventajas que permite perder el rostro individualmente. La

18. «El repertorio es, a la vez, un concepto estructural y un concepto cultural que incluye no sólo lo que los contendientes hacen, cuando están inmersos en un conflicto contra otros, sino lo que saben hacer y lo que los otros esperan que hagan» (Tarrow, 2004: 59).

19. Al respecto plantea Tarrow: «los cambios en la estructura de las oportunidades y las restricciones políticas crean los principales incentivos para iniciar nuevas etapas de acciones colectivas» (2004: 29). 
multitud de la marcha genera sensación de protección entre los asistentes porque disuade la acción marihuanofóbica (Restrepo, 2017).

La multitud anula en cierto sentido la individualidad, esto permite anonimato, no ser identificado. En este sentido, Laura Blanco, presidenta de los clubes cannábicos de Uruguay, afirmó: «en nuestras primeras marchas invitábamos a las personas a que saliéramos como en carnaval y así cada quien podía llevar una máscara o un disfraz. Esto permitió que muchos salieran a la calle con menor miedo al estigma por ser consumidores» (Entrevista personal, Laura Blanco, presidenta de los clubes cannábicos de Uruguay, Medellín, mayo de 2014). El miedo a un reconocimiento público tiene fundamento en la persecución al consumidor. El carácter colectivo y festivo contribuye a enfrentar tal sentimiento que puede conducir a la parálisis. ${ }^{20}$

La marcha es en sí misma un hecho político. ${ }^{21}$ Dado el contexto de exclusión que viven los consumidores, la sola concentración de miles de personas fumando marihuana en lugares públicos constituye un acto político, en palabras de un activista de Pereira: «Una subjetividad está en resistencia cuando va y pega un bareto ${ }^{22}$ en un parque donde es ilegal ¿si me entendés? O sea, ahí ya hay una acción de resistencia, porque está haciendo algo ilegal en un espacio público» (Entrevista personal, Albert, Pereira, marzo de 2015). En un contexto de tales características, la mera presencia de los marihuaneros en el espacio público es una forma de reivindicar su existencia social y política; justamente algo que la política de guerra contra las drogas ha intentado evitar.

La marcha es uno de los principales repertorios implementados por los cannábicos, pero no es el único. También han utilizado otros repertorios de acción como puede verse a continuación:

En diversas ciudades alrededor del mundo, se realizan actividades a lo largo de todo el mes de Mayo, como este año se hará en Colombia, se incluyen actividades tales como: marchas, concentraciones, plantones, conferencias, foros, mítines, reuniones, fiestas, conciertos, festivales, mesas de información y demás actividades relacionadas con la información, el apoyo y la defensa del cannabis, sus derivados, usos y sus usuarios alrededor del mundo (Marcha Mundial Pro-cannabica, Facebook, mayo de 2011).

20. «Para mantener las acciones que desafían el orden público se precisa un alto nivel de compromiso, la capacidad de sorprender a las autoridades y resistir las tentaciones tanto de la violencia como del convencionalismo» (Tarrow, 2004: 144).

21. «Al permanecer sentados, de pie o marchando junto a otros agresivamente en un espacio público, los manifestantes afirman su identidad y refuerzan su solidaridad» (Tarrow, 2004: 143).

22. En este contexto «pegar un bareto» quiere decir liarlo y fumárselo. 
Para comprender el repertorio de acción, también deben considerarse rasgos preponderantes de los activistas, como el nivel educativo. Por ejemplo, los cannábicos que lideran los colectivos pueden catalogarse, siguiendo a Tarrow, bajo el signo de la profesionalización de los activistas (Tarrow, 2004: 189). Un resultado de activistas que consideran importante educarse para así resolver o enfrentar mejor los problemas que los incumbe y de estudiantes universitarios o profesionales que en su formación terminan como activista:

Cuando estuve en la universidad y comencé a darme cuenta de que se podía comenzar a argumentar desde otro tipo de acciones diferentes a la rebeldía, a la acción digamos violencia concreta me comencé a dar cuenta que uno podía comenzar a argumentar, podíamos comenzar a estudiar y ahí me comencé a dar cuenta que la gente contradictoria frente al tema se quedaba sin argumentos, ya en ese momento pasé del odio a la motivación y a las ganas de comenzar a hacer el activismo (Entrevista personal, Albert, Pereira, marzo de 2015).

Albert estudió sociología, es uno de los tantos activistas cannábicos universitarios que hacen parte de la CCC. Este repertorio realizado en la dimensión offline, ha sido posible al papel jugado por la organización de los cannábicos acudiendo al uso de las nuevas tecnologías de la comunicación como el internet y, en particular, la red social Facebook.

\section{Repertorio online}

En el segundo apartado de este artículo aparece la relación que estableció Olmes Ortiz con David Arango, después de las dificultades que llevaron a Olmes a desistir de realizar la marcha por la poca asistencia de marihuaneros. Tal como señala Olmes, la presencia de David y, luego, de Don Marcha, en el manejo de redes sociales y su pasión por el tema del cannabis, ha permitido realizar diferentes marchas en las cuales es notorio el incremento de asistentes y de las formas de manifestarse colectivamente. La experticia de David y Don marcha en comunicación por las redes sociales y el carisma de Olmes se configuraron de manera tal que forjaron un «imán» que atrajo a otros activistas y simpatizantes que fueron dando lugar a una acción colectiva en pleno corazón de las principales ciudades del país. La capacidad de difusión de conocimiento e información hizo parte del repertorio de acción empleado por los activistas. Según Don marcha:

Realmente el sitio web empieza de una manera de difusión de información, más que todo nos damos cuenta que tanto en los usuarios como en los no usuarios de cannabis, 
existe el mismo desconocimiento frente a la planta [...]. Compartir a veces un chiste, a veces una foto, a veces un buen comentario, una buena recomendación, hizo que la página Comunidad Cannábica Colombiana fuera creciendo (Entrevista personal, David Ponce, Comunidad Cannábica Colombiana, Medellín, marzo de 2015).

Los activistas cannábicos hacen su propio balance del uso de Facebook: «La página del Carnaval Cannábico Colombiano en solo 3 meses gusto a más de 4 mil personas. Tuvo un alcance de 220.000 personas y llegó de manera directa a más de 30 mil. Una página abierta, administrada por más de 30 activistas, colectivos e individuos comprometidos con la causa» (Marcha Mundial Pro-cannábica, Facebook, 2013). Pero no solo creció el número de seguidores de la página, sino también la presencia de activistas ${ }^{23}$ en las principales ciudades del país. El potencial de Facebook en la consolidación de la marcha y el movimiento lo reconocen los mismos activistas, dice Don marcha:

David es una persona obviamente joven y tiene acceso a internet, a diferencia de Olmes, que apenas hoy se está acercando a este tipo de tecnologías. David consulta en internet y descubre que en el mundo, el primer sábado de mayo se celebra la Global Marihuana March, la Marcha Mundial de la Marihuana como la llamamos nosotros, en diferentes países del mundo y deciden, ya en el año 2009, juntos hacer la primera Marcha Mundial de la Marihuana Medellín 2009, donde por primera vez se reúnen más de 2.50o personas saliendo desde el Teatro Pablo Tobón Uribe manifestándose por el cannabis en paz, en armonía y sin generar ningún altercado (Entrevista personal, David Ponce Patiño, Comunidad Cannábica Colombiana, Medellín, marzo de 2015).

La internet permite a las personas acceder a información y conocimiento. Ello es posible porque internet y una red como Facebook integran múltiples canales de comunicación (Dalsgaard 2016:99). Las personas tienen así la libertad de consultar distintas fuentes de información para formarse el propio juicio y tomar decisiones. El conocimiento tiene fuertes implicaciones en las vidas de las personas, activistas como David Arango son contundentes con el tema:

¿Qué le quita a uno ese miedo a actuar? El conocimiento, parce, saber, primero que no estás solo, porque hay muchos más y de ahí se va nutriendo, desde datos hasta cómo esquivar tombos y de cómo hablarles, hasta leyes y demás, entonces cuando usted

23. Para autores como Fernández Prados (2012) puede hablarse de ciberactivistas y distinguir entre ellos tres tipologías de activismo: activismo digital, hacktivismo y ciberterrorismo; los tres están relacionados con la protesta electrónica. En este artículo no nos extenderemos sobre este aspecto, solo señalamos que el activismo digital viene marcando las acciones cannábicas. 
sabe tiene argumentos, parce y no tiene por qué huir, pues no sé, se le quita el miedo (Entrevista personal, David Arango, Comunidad Cannábica Colombiana, Medellín, agosto de 2015).

La internet contribuye para que las personas pierdan el miedo a la actuación pública al facilitarles la obtención de conocimiento para elaborar los argumentos con los cuales participan del debate público. El conocimiento también hace referencia a la posibilidad de obtener información para contactar a otras personas con similares inquietudes a nivel local, nacional y global. La internet en general abre la opción a un universo de visiones, argumentos, datos, etc. Esta apertura remueve el lugar tradicional de los medios masivos de comunicación que ven así afectado su monopolio informativo. El rol de la internet en la consolidación de la CCC ha sido relevante porque ha permitido varios asuntos, como que los activistas tengan otras versiones sobre las drogas y las políticas sobre ellas, también ha favorecido el conocimiento entre los activistas y el obrar colectivamente. Dice Don marcha al respecto:

El nacimiento de la CCC en la ciudad está muy ligado al aumento de los canales y del acceso a la información desde el lado de internet, la Comunidad Cannábica Colombiana empezó con eso, con un sitio web, donde ya el internet nos daba la posibilidad de una difusión de información que no íbamos a encontrar en los medios tradicionales, ni siquiera en la prensa, en la televisión o en la radio se tocaba el tema y si se tocaba no era para hablar bien del mismo, realmente el tema se ha tocado para seguir satanizando y aumentando el prejuicio y el perjuicio contra el cannabis y sus usuarios. Entonces internet nos empieza a permitir difundir información, también acceder a información de primera mano de otros agentes en diferentes partes del mundo (Entrevista personal, David Ponce Patiño, Comunidad Cannábica Colombiana, Medellín, marzo de 2015).

Los repertorios de acción en su conjunto han posibilitado que la CCC incida en la agenda pública, por ejemplo, sectores de la CCC, en acuerdo con indígenas y campesinos cultivadores de marihuana, participaron de los debates que, en el año 2016, condujeron a la legalización de la marihuana medicinal. Igualmente, la CCC ha participado de las discusiones de la política de drogas convocada por el Ministerio del Interior y de los eventos realizados en el marco de la negociación de paz de La Habana para debatir el punto de solución a las drogas ilícitas. 


\section{Consideraciones finales}

En el surgimiento y consolidación de la CCC las redes sociales como el Facebook han jugado un papel importante. El activismo offline ha sido fortalecido por las posibilidades que ofrece el activismo online. Ambos se entrelazan constituyendo un repertorio de acción política que permite la conformación organizativa de un sujeto colectivo y la realización misma de la acción política cannábica tendiente al cambio de la política de guerra contra las drogas.

En Facebook existe una relación social, existe el otro con el cual puede establecerse conexión y compartir vídeos, fotos, documentos, noticias, etc. (Dalsgaard, 2016: 98). Facebook permite compartir con el otro una parte de la experiencia. Facebook e internet refuerzan el trabajo en la vida real, offline (Dalsgaard, 2016: 98). La relación entre el online y el offline podemos abordarla como dos dimensiones actuales para la acción política de organizaciones guiadas por unos propósitos definidos (Dalsgaard, 2016). El internet en general y Facebook en particular han posibilitado adelantar procesos organizativos de corte nacional y global (Castell, 2012). Este tipo de medio comunicativo ha permitido el contacto entre activistas y simpatizantes del movimiento cannábico. Situación conducente al conocimiento mutuo e identificación colectiva para la constitución de confianza para asumir el riesgo (Tilly, 2004) de enfrentar colectivamente el estigma en su situación extrema: la marihuanofobia.

Las redes sociales movilizadas por internet han posibilitado la formación colectiva de los consumidores de cannabis en Colombia. En internet y en redes sociales como Facebook «los activistas y sus organizaciones prolongan sus acciones a través de la red» (Fernández Prados, 2012: 634). En movimientos como el cannábico, la relación personal entre los principales activistas procedía de un conocimiento previo relacionado con el mundo de la marihuana. Para esta clase de relación aplica la anterior cita, la red social permitió prolongar una relación preestablecida. Pero la red no solo tiene ese sentido, en ella también pueden surgir las relaciones gracias a las nuevas tecnologías (Dalsgaard 2016: 99). Las personas se conocen por este medio. Sin embargo, no debemos sobrevalorar la importancia de este aspecto, sigue vigente la discusión entre quienes consideran que el uso de la red facilitará y alentará nuevas formas de activismo político, mientras que otros creen que el uso de la red fortalecerá, pero que no transformará patrones existentes de participación política (Fernández Prados, 2012: 635).

No obstante tal advertencia, podemos concluir afirmando que el rol desempeñado por Facebook en la formación individual y colectiva del activismo cannábico en Colombia coincide con la reflexión de Tarrow cuando afirma que ejercer el derecho a la protesta «no significa que los movimientos se limiten a protestar; también cons- 
truyen organizaciones, elaboran ideologías y socializan y movilizan al electorado, al tiempo que sus miembros participan en su propia formación y en la creación de identidades colectivas» (Tarrow, 2004: 24). La red social crea y recrea la organización con su manifestación pública colectiva incidiendo de manera diferenciada en la dimensión online y en la dimensión offline ${ }^{24}$ ambas constitutivas del movimiento cannábico colombiano. Tiene así surgimiento una fuerza social y política, una acción colectiva contenciosa (Tarrow, 2004), el movimiento cannábico colombiano, una voz discordante en el coro de la política de guerra contra las drogas.

\section{Referencias}

BOURGOIS, P. (2010). En busca de respeto. Vendiendo crack en Harlem. Buenos Aires, Argentina: Siglo XXI.

CAMPS, V. (2011). El gobierno de las emociones. Barcelona, Herder.

CASTELLS, M. (2012). Redes de indignación y esperanza. Madrid, Alianza.

CORTEŚ, F. (2002). Justicia y exclusión: elementos para la formulación de una concepción igualitaria de justicia. Estudios Políticos. (20), 157-178. Recuperado de: http://revistaestudiospoliticos. udea.edu.co/index.php/estudiospoliticos/article/view/17479

DALSGAARD, S. (2016). The Ethnographic Use of Facebook in Everyday Life. Anthropological Forum. 26 (1), 96-114. doi: 10.1080/o0664677.2016.1148011

ESCOHOTADO, A. (1998). Historia de las drogas. vol.3. Madrid: Alianza.

FERNÁNDEZ PRADOS, J. S. (2012). Ciberactivismo: conceptualización, hipótesis y medida. Arbor Ciencia, Pensamiento y Cultura. 18 (756), 631-639. doi: 10.3989/arbor.2012.756n40o1

Gobierno Nacional de la República de Colombia, Ministerio de Justicia y del Derecho. Observatorio de Drogas de Colombia, Ministerio de Salud y Protección Social, Oficina de las Naciones Unidas contra la Droga y el Delito-UNODC-, la Comisión Interamericana para el Control del Abuso de Drogas -CICAD-, OEA y Embajada de los Estados Unidos en Colombia - INL. (2014). Estudio nacional de consumo de sustancias psicoactivas en Colombia, Informe del año 2013. Bogotá D.C.

GOFFMAN, E. (2003). Estigma. La identidad deteriorada. Buenos Aires: Amorrortu.

GUBER, R. (2001). La etnografia. Método, campo y reflexividad. Bogotá: Norma.

24. De Facebook a la calle hay una gran distancia, no todo activista de redes es propiamente un activista de calle, como tradicionalmente se dice. 
HONNETH, A. (1997). La lucha por el reconocimiento. Barcelona: Crítica.

HONNETH, A. (2012). Reificación. Argentina: Katz.

RESTREPO PARRA, A. (2017). El derecho a consumir marihuana. Estudios Políticos. (50). (En prensa).

PEREA, C. M. (2016). Limpieza social una violencia mal nombrada. Bogotá: Centro Nacional de Memoria Histórica, Universidad Nacional de Colombia.

TARROW, S. (2004). El poder en movimiento. Madrid: Alianza.

TILLY, CH. (2004). ¿De dónde vienen los derechos? Madrid, Sociológica. 19 (55), 273-30o. Recuperado de: http://www.revistasociologica.com.mx/pdf/5510.pdf 